Association for Information Systems AIS Electronic Library (AISeL)

WHICEB 2018 Proceedings

Wuhan International Conference on e-Business

Summer 6-30-2018

\title{
Quantifying the Effect of Mobile Channel Visits on Firm Revenue
}

Yingnan Zhao

School of Business, Nanjing University, Nanjing, 210093, China

Quansheng Wang

School of Business, Nanjing University, Nanjing, 210093, China

Peijian Song

School of Business, Nanjing University, Nanjing, 210093, China

Fan Feng

School of Business, Nanjing University, Nanjing, 210093, China

Follow this and additional works at: http://aisel.aisnet.org/whiceb2018

\section{Recommended Citation}

Zhao, Yingnan; Wang, Quansheng; Song, Peijian; and Feng, Fan, "Quantifying the Effect of Mobile Channel Visits on Firm Revenue" (2018). WHICEB 2018 Proceedings. 56.

http://aisel.aisnet.org/whiceb2018/56

This material is brought to you by the Wuhan International Conference on e-Business at AIS Electronic Library (AISeL). It has been accepted for inclusion in WHICEB 2018 Proceedings by an authorized administrator of AIS Electronic Library (AISeL). For more information, please contact elibrary@aisnet.org. 


\title{
Quantifying the Effect of Mobile Channel Visits on Firm Revenue
}

\author{
Yingnan Zhao, Quansheng Wang, Peijian Song ${ }^{*}$, Fan Feng \\ School of Business, Nanjing University, Nanjing, 210093, China
}

\begin{abstract}
The explosive penetration of mobile devices is one of the most prominent trends in e-business. Although the importance of mobile channel has prompted growing literature, little is known about the revenue implications of customer visit toward mobile channel. This study examines (1) the differential effect of mobile visits in affecting firm revenue (i.e. mobile vs. desktop visits), and (2) which type of mobile visits are more effective (i.e., direct vs. search engine and referral traffic; visits for high vs. low involvement products). We collect an unique objective daily data from a leading online travel agency in China. With a vector autoregressive (VAR) method, we find that, compared with desktop channel, mobile channel visits have shorter carryover effect, but larger short-term effect on firm revenues. Further, mobile channel has larger short-term effect on firm revenues for search engine traffic and lower involvement products. Our findings provide important theoretical contributions and notable implications for mobile commerce strategy.
\end{abstract}

Keywords: mobile channel, mobile commerce, firm revenue, vector autoregressive method

\section{RESEARCH QUESTION}

The explosive penetration of mobile devices is one of the most prominent trends in customer-firm interactions. According to a survey by Forrester Research, 91\% online retailers in the U.S. have a mobile strategy in place or in development, $48 \%$ retailers have a mobile website. Despite the emerging trends of mobile commerce, marketers' beliefs about the value of mobile channel seem to be at best mixed, if not negative. The importance of mobile channel has prompted growing literature focused on the mobile channel transactions. However, little is known about the transaction revenue implications of customer visit toward mobile channel, and what is the difference between mobile channel and desktop channel in value creation. Furthermore, traffic source characteristics were largely overlooked in the literature. Hence, we explicitly quantify different value mobile channel traffic monetized, and explore how different traffic sources and products might differentially contribute to transactions.

\section{MAJOR RESEARCH FINDINGS}

We analyze characteristics between mobile and desktop channel including convenience, targeting, search cost and payment risk. Based on information process theory and decision-making literature, we compare their effects in short- and long- term. On the one hand, mobile channel can support time-critical activities and facilitate immediate transactions because of convenience. Marketers can also target location-sensitive promotional offers to mobile devices users ${ }^{[1]}$. When customers receive the timely location-based promotion, they will transact immediately if they are interested in. Therefore, the whole duration between need recognition and transaction is short in mobile channel, and mobile visits have larger effect on short-term revenues than desktop visits. On the other hand, low search cost makes it feasible for customers to acquire full knowledge of product information in the search stage. And because of the advantage in transaction risk, customers will transaction high risk products in desktop channel and engage in extensive searches which further increases the duration between need recognition and transaction. Therefore, compared with mobile channel visits, the desktop channel visits have longer carryover effect on firm revenues. Considering the mobile visits mainly have short-term effects on firm revenue, we differentiate different types of mobile visits: three sources of traffic and

\footnotetext{
Corresponding author. Email: songpeijian@nju.edu.cn (Peijian Song), zhaoyingnan@ smail.nju.edu.cn (Yingnan Zhao), wangqs@nju.edu.cn (Quansheng Wang)
} 
products with different level of involvement.

We choose online travel agency as our empirical setting. We estimated a VAR model, where endogenous variables are traffic and transaction revenue in both mobile and desktop channel. We also included a vector of the exogenous variables such as, an intercept $C$; a deterministic-trend variable $T$, which captured the impact of the omitted, gradually changing trend of the variables; indicator for holidays $\mathrm{H}$ (holidays as 1 and non-holidays as 0). The VAR specification is given by Equation 1:

$$
\begin{gathered}
{\left[\begin{array}{l}
\ln T M_{t} \\
\ln T D_{t} \\
\ln R M_{t} \\
\ln R D_{t}
\end{array}\right]=\left[\begin{array}{l}
C_{T M} \\
C_{T D} \\
C_{R M} \\
C_{R D}
\end{array}\right]+\left[\begin{array}{l}
\delta_{T M} \\
\delta_{T D} \\
\delta_{R M} \\
\delta_{R D}
\end{array}\right] \times \mathrm{T}+\left[\begin{array}{l}
\gamma_{T M} \\
\gamma_{T D} \\
\gamma_{R M} \\
\gamma_{R D}
\end{array}\right] \times \mathrm{H}} \\
+\sum_{\mathrm{j}=1}^{\mathrm{J}}\left[\begin{array}{llll}
\varphi_{11}^{j} & \varphi_{12}^{j} & \varphi_{13}^{j} & \varphi_{14}^{j} \\
\varphi_{21}^{j} & \varphi_{22}^{j} & \varphi_{23}^{j} & \varphi_{24}^{j} \\
\varphi_{31}^{j} & \varphi_{32}^{j} & \varphi_{33}^{j} & \varphi_{34}^{j} \\
\varphi_{41}^{j} & \varphi_{42}^{j} & \varphi_{43}^{j} & \varphi_{44}^{j}
\end{array}\right]\left[\begin{array}{l}
T M_{t-j} \\
T D_{t-j} \\
R M_{t-j} \\
R D_{t-j}
\end{array}\right]+\left[\begin{array}{l}
\varepsilon_{T M, t} \\
\varepsilon_{T D, t} \\
\varepsilon_{R M, t} \\
\varepsilon_{R D, t}
\end{array}\right]
\end{gathered}
$$

where TM is traffic in mobile channel, TR is traffic in desktop channel, RM is transaction revenue in mobile channel, RD is transaction revenue in desktop channel, $t$ refers to days, $\mathrm{j}$ equals the number of lags included, and $\varepsilon$ is white-noise disturbances distributed as $\mathrm{N}(0, \Sigma)$. Both $\delta, \gamma$ and $\varphi$ are parameters that need to be estimated. Following Dekimpe and Hanssens ${ }^{[2]}$, we used Generalized IRFs to ensure that the order of variables in the system did not affect the results. Standard errors were derived by simulating the fitted VAR model by Mont Carlo simulation with 1,000 runs to test the statistical significance of parameters $(p=0.10)$. Duration of carryover effects were measured by wear-out time, that is the lag number of periods it takes after the peak impact before transaction revenue effects die out. We determined the duration of impact as equal to the last period in which the IRF value had a $|\mathrm{t}|$-statistic greater than 1.96.

We find that mobile channel and desktop visits show a significant positive relationship with firm revenue (0.19 and 0.12 basis points respectively, $p<0.01)$ for short-term. This finding suggests that mobile channel visits are more effective in affecting firm revenue. Desktop channel visits demonstrate a longer wear-out time (10 days) than mobile channel visits ( 2 days), although insignificant in the long-term. In addition, search engine visits have a significant relationship with firm revenue $(0.12$ basis points, $p<0.10)$ in the short-term, while referral visits are not significantly related to firm revenue $(0.06$ basis points, $p>0.10)$. Direct visits show an insignificant effect in the short-term (0.00 basis points, $p>0.10)$, and the coefficient of direct visits is smaller than that of search engine and referral visits. Referral traffic does not achieve significant effect that may result from the methods diverting referral traffic. This kind of traffic are without explicit shopping goal. In addition, due to some of the significant technical limitations display advertisements face in mobile, some literatures suggest that this kind of ads may not be effective. Mobile visits for high involvement products are positively associated with firm revenue $(0.16$ basis points, $p<0.01)$ in the short-term, and mobile visits for low involvement products are also significantly but more effectively associated with firm revenue ( 0.23 basis points, $p<0.05)$. Thus, compared with high involvement products, mobile visits of low involvement products have a larger short-term effect on firm revenues. Moreover, results that mobile visits for both high and low involvement products are not significantly associated with firm revenue in the long run.

\section{CONCLUSIONS}

Given the increasing penetration of mobile devices among consumers, a better understanding of mobile channel value creation is needed. This study finds that, compared with desktop channel, mobile channel visits have shorter carryover effect, but larger short-term effect on firm revenues. Further, mobile channel has larger short-term effect on firm revenues for search engine traffic and lower involvement products. 


\section{ACKNOWLEDGEMENT}

This research was supported by the National Natural Science Foundation of China under Grant 71472083, 71372035.

\section{REFERENCES}

[1] Hui, S. K., Inman, J. J., Huang, Y., \& Suher, J. 2013. The effect of in-store travel distance on unplanned spending: Applications to mobile promotion strategies. Journal of Marketing, 77(2): 1-16.

[2] Dekimpe, M. G. \& Hanssens, D. M. 1999. Sustained spending and persistent response: A new look at long-term marketing profitability. Journal of Marketing Research, 36(4): 397-412. 